\title{
ə EDITORIAL
}

\section{Vegetation classification goes open access}

\author{
Florian Jansen¹, Idoia Biurrun², Jürgen Dengler ${ }^{3,4,5}$, Wolfgang Willner 6 \\ 1 Landscape Ecology, Faculty of Agricultural and Environmental Sciences, University of Rostock, Rostock, Germany \\ 2 Plant Biology and Ecology, University of the Basque Country UPV/EHU, Bilbao, Spain \\ 3 Vegetation Ecology, Institute of Natural Resource Sciences (IUNR), Zurich University of Applied Sciences (ZHAW), Wädenswil, Switzerland \\ 4 Plant Ecology, Bayreuth Center of Ecology and Environmental Research (BayCEER), University of Bayreuth, Bayreuth, Germany \\ 5 German Centre for Integrative Biodiversity Research (iDiv) Halle-Jena-Leipzig, Leipzig, Germany \\ 6 Department of Botany and Biodiversity Research, University of Vienna, Vienna, Austria \\ Corresponding author: Florian Jansen (florian.jansen@uni-rostock.de)
}

Academic editor: Wolfgang Willner • Received 20 April 2020 • Accepted 20 April 2020 • Published 4 May 2020

\begin{abstract}
With this inaugural editorial, we introduce Vegetation Classification and Survey (VCS), the new gold open access (OA) journal of the International Association for Vegetation Science (IAVS). VCS is devoted to vegetation classification at any spatial and organisational scale and irrespective of the methodological approach. It welcomes equally case studies and broad-scale syntheses as well as conceptual and methodological papers. Two Permanent Collections deal with ecoinformatics (including the standardised Database Reports published in collaboration with GIVD, the Global Index of Vegetation-Plot Databases) and phytosociological nomenclature (edited in collaboration with the respective IAVS Working Group). We discuss the advantages of $\mathrm{OA}$ as well as challenges and drawbacks caused by the way it is currently implemented, namely "pay for flaws" and publication impediments for scientists without access to funding. Being a society-owned journal, editorial decisions in VCS are free from economic considerations, while at the same time IAVS offers significant reductions to article processing charges (APCs) for authors with financial constraints. However, it is recognised that sustainable OA publishing will require that payment systems are changed from author-paid APCs to contracts between the science funding agencies and publishers or learned societies, to cover the production costs of journals that meet both quality and impact criteria.
\end{abstract}

Abbreviations: APC $=$ article processing charge, GIVD = Global Index of Vegetation-Plot Databases, IAVS = International Association for Vegetation Science, JVS = Journal of Vegetation Science, OA = open access, VCS = Vegetation Classification and Survey.

\section{Keywords}

article processing charge (APC), double-blind, learned society, open access, open data, peer review, phytosociological nomenclature, science funder, serial crisis, vegetation classification, vegetation-plot database

\section{Introduction}

Welcome to the first issue of the new journal Vegetation Classification and Survey (VCS).

After one year of intensive discussion, the Council of the IAVS decided in June 2019 to start VCS as a third association-owned journal, alongside the Journal of Vegetation Science (JVS) and Applied Vegetation Science (AVS), which means that now the whole spectrum of vegetation science is covered by IAVS-owned journals.

The scope of VCS is focused on vegetation typologies and vegetation classification systems, their methodological foundation, their development and their application. The journal publishes original papers that develop 
new typologies as well as applied studies that use such typologies, for example, in vegetation mapping, ecosystem modelling, nature conservation, land use management, or monitoring. We particularly encourage methodological studies that design and compare tools for vegetation classification and mapping, such as algorithms, databases and nomenclatural principles, or are dealing with the conceptual and theoretical bases of vegetation survey and classification. VCS is for the international audience, meaning that large-scale studies are preferred, but regional studies will be considered if they fill important knowledge gaps or are used to develop and present new methods. Apart from "regular" articles, VCS will include two special sections, called "Permanent Collections":

The Collection Ecoinformatics invites papers presenting vegetation-plot databases and other ecoinformatics data sources relevant for vegetation classification as well as concepts, methods and tools for using these. VCS has established a formal collaboration with the Global Index of Vegetation-Plot Databases (GIVD; http://www.givd. info) and it will serve as an outlet for reports on GIVD activities, Short Database Reports (1-2 printed pages, no text except abstract, no references) and Long Database Reports (3-15 printed pages). Submissions of Database Reports must be accompanied by a recent Fact Sheet from the GIVD website.

The Collection Phytosociological Nomenclature focuses on nomenclature issues for syntaxa. We encourage comprehensive nomenclatural revisions of major syntaxa, analyses of nomenclatural problems related with the names of wide-spread high-rank syntaxa as well as Forum Papers on general nomenclatural issues that are of interest to an international readership. Further, official documents issued by the Working Group for Phytosociological Nomenclature (GPN) of the IAVS, such as Reports, Decisions and Proposals, will be published in this section.

It has certainly not gone unnoticed that the editorial team of VCS is largely identical with the one that has been responsible for Phytocoenologia during the last five years (Jansen et al. 2016; Biurrun et al. 2019). The reasons why we and IAVS decided to start a new journal with a new publisher are manifold. The situation resembles the launch of JVS in 1990. Indeed, the words of Eddy van der Maarel in the inaugural editorial of JVS (referring to the journal Vegetatio, now Plant Ecology), could equally be applied to summarise our own decision: "not only did IAVS as a society lack a real influence on the journal, [...] the journal became a luxury for libraries in rich countries" (van der Maarel 1990). We hope that you as readers and authors will now follow us into a successful future of academic exchange and development. We, the Chief Editors of the old and the new journal, are excited about the new possibilities and we hope for your support. In particular, we want to thank the members of our very diverse editorial team. Representatives from many regions of the world have agreed to support the journal and will guarantee an unprecedented level of expertise to cover research on vegetation from all around the globe.
Together with the new journal title and the new publisher, we also decided to implement some additional major changes. The most important ones are to go open access and to introduce double-blind peer review.

\section{Open research}

It is acknowledged that research which is freely available has a greater impact than research hidden behind a payment wall (Antelman 2004), benefiting science by accelerating dissemination and the uptake of research findings (Eysenbach 2006), especially for developing countries (Evans and Reimer 2009). Other academic, economic or societal benefits of an open research approach have been identified (Tennant et al. 2016) and as part of this approach the availability of primary data is recognised as being crucial for the reproducibility of analyses (Reichman et al. 2011) and must be encouraged.

The development of the Internet and how it redefined communication and publishing has been the main driver of the open access (OA) movement (Laakso et al. 2011). Making printed versions of articles obsolete, the costs per research article theoretically should have decreased as a result of not investing material resources in publication printing and distribution. Instead, the subscription prices within the traditional publishing model have increased steadily, enabled by the inelastic demand for finding prestigious publication venues for authors.

\section{The way towards open access}

The resulting OA initiatives have led to "gold open access" venues, these are journals that solely publish open-access papers with the costs of publishing either marginalised by the publication work being undertaken on an unpaid voluntarily basis or paid for by the authors via APCs. At present, however, "green open access" (i.e., the publication of accepted but unformatted articles on personal webpages), and "hybrid" models are still more common. The latter have become standard in most traditional journals. Hybrid OA means that additional to the normal subscription fee for a journal, individual papers can be paid-off from the pay wall restrictions but in most cases without a reduction of the journal subscription fee. This effectively means "double dipping" for the publisher (Cheung 2015), making it attractive within traditional business models, but without generating momentum for a general shift towards OA. Therefore, such hybrid models have been excluded from the OA payment regulations of many science funding institutions.

The biggest challenge of OA is located outside of science and is a problem of financial cash flow. As exemplified in Geschuhn (2015) there probably is enough money in the system to cover all costs of OA publishing. Publication costs are much more transparent in OA than in traditional subscription models and average costs have 
been estimated to be much lower. For 2015, a global expenditure of at least EUR 7.6 billion, mostly in the form of subscription fees, and a production of 1.5 to 2 million papers has been calculated, resulting in an allocation per article of EUR 3,800 to 5,000 (Geschuhn 2015). This money would need to be transferred from subscription fees paid by libraries (mainly for huge bundles of journals from a small number of mega-publishers) to the APCs for OA papers. Only if the money is re-purposed from subscription fees to individual or bundled APCs, transforming the underlying business model for publishers and overcoming the "serial crisis" (McGuigan and Russell 2008), will OA be as disruptive as predicted. Until recently the most target-oriented step has been the introduction of "offsetting" models instead of hybrid approaches. Offsetting means that for every OA article the subscription fee for the journal is effectively reduced, making the transition between subscription and pre-publication business models transparent and flexible.

A widely perceived step towards a complete transition to OA was the so-called project DEAL between German science organisations and major global publishers in 2019 and 2020 (Wiley and MPDL Services 2019; SpringerNature and MPDL Services 2020). The core objective of this deal is open access to all research articles written by corresponding authors based at German science institutions, while paying for such services with a model based on the number of articles published by the institution. If this model could be adopted in more countries, it could become a very powerful driver for a fast shift to OA, because in this scenario APCs do not have to be covered by the authors of a paper but are being be paid by a country's research institutions.

\section{Challenges of open access}

While in the initial phase of the OA movement a broad believe was predominant among scientists, librarians, and science funders that "gold open access" would be the solution to many of the problems of the traditional subscription journal system, nowadays scientists are often disillusioned by how OA is implemented in practice:

Firstly, gold open access often only transfers the barriers from one place to another. While published science in an OA world is accessible to everybody, it does depend on the financial capabilities of authors and their institutions whether a relevant piece of science is published or not; as long as it is based on APCs and no non-discriminatory refunding mechanism exists. In the traditional publication system, libraries in rich countries subsidize the production of high-quality journals and good scientific work is accepted irrespective of the origin and financial capabilities of the authors. Getting access to a published non-OA article, even if your own library has not subscribed, is in practice much easier than securing funds for your own OA manuscript. In fact, APCs are not only prohibitive for authors from developing countries, but also for many au- thors in rich countries who are not associated with large scientific institutions.

Secondly, it has been widely perceived in the scientific community that a business model that is built on APCs might jeopardize the quality of scientific journals. Generally, APCs incentivize quantity rather than quality: the more articles are published, the more revenue is generated by the publisher, at least in the short to medium term. Accordingly, many new OA publishers have been established promising faster and higher acceptance rates. In order to ensure this promise, it is often the employees of the publisher, instead of respected and independent scientists, that make editorial decisions. However, also traditional scientific publishers have opened new low-profile OA journals to which they redirect those articles that did not reach the standards required for acceptance in their own high-profile subscription journals. We call this a "pay for flaws" model. It should also be recognised that there are still hardly any top-tier journals among the gold OA journals, neither in ecology nor in multidisciplinary sciences.

\section{Ways to overcome the challenges}

They are far from trivial, but there are ways out of this labyrinth. Science funders should not pay gold OA fees independent of the journal's quality, but should look more closely into editorial practices and base payment on the average quality of the outcome (e.g., citation rates). Editors have to be independent and not employees of the publisher. Usually reviewers and editors have made a big contribution to the quality of an article before it reaches the scientific public and there must be no incentives or pressure to shortcut this process. Journals that violate such ethical standards must be excluded from receiving APCs paid from public money. Moreover, for those journals meeting specific quality standards funding agencies should cover different levels of cost depending on the quality level of the journal, for example by setting different thresholds depending on the impact quantile of the respective discipline to which the journal belongs.

Science funders also need to nurture science as a whole, not only those scientists employed at high-profile institutions within their own country. Gold OA will only work properly when we overcome the current situation of individual APCs paid by authors and replace this with payments from consortia of science funders and institutions to publishers or learned societies, to produce high-quality gold OA journals.

\section{The role of learned societies}

Learned societies have always played a major role in scientific publishing. The first scholarly journals were founded by learned societies such as the Philosophical 
Transactions by the Royal Society of London in 1665. Learned societies will also play an indispensable role in the transition to OA, fostering scientific excellence beyond economic stimulus. Currently, however, the incentives for learned societies are detrimental to OA as they are paid by publishers for the journals published under their name and editorial team, as is the case for the two long-standing IAVS journals. This is often the predominant source of income for a society which in turn is used to fund scientific activities, such as grants and prizes for young scientists or discounts on conference fees for participants with financial constraints. On the other hand, membership is coupled with discounts on journal subscription fees, which is often the major incentive to become a society member. At least the latter can be replaced by switching from an incentive for readers to incentives for authors by reducing the APCs, as is done by the IAVS in the form of a $10 \%$ discount for VCS for IAVS members.

\section{How VCS addresses the challenges}

We Chief Editors fully support the open research philosophy. However, we also see the drawbacks of the current implementation of $\mathrm{OA}$ for science in general and the problems that APC OA causes for many of our authors.

As VCS is owned by a respected scientific association, which controls the publication policy and appoints the Chief Editors, full economic independence from the publisher is guaranteed. This means that we do not promise that the acceptance of an article in our journal will be fast or the revisions easy. However, both authors and readers can trust on the quality of all articles when they are published.

It is important that authors consider the bigger picture if confronted with an APC bill. The whole scientific community is asked to work within sustainable financing and it should be recognised that the IAVS will do its best to distribute financial burdens fairly, by offering reductions and waivers for authors until more countries find solutions to refund the cost of pre-publication fees. Authors should discuss with co-authors the best solution for your manuscript. If in doubt, please contact the editors. The distribution of good scientific research should not be hindered by financial obstacles!

You can find the current APCs for VCS, set by the IAVS Publication Committee, at https://vcs.pensoft.net/ about\#Article-Processing-Charges. The comparatively low base price is further reduced for IAVS members, Editorial Board members, authors from countries with low income or with financial hardship. Please talk to your research institution about possibilities for refunding the costs. An increasing number of institutions and funding agencies are happy to cover the costs for gold open access journals such as VCS, knowing that in the long term this is an opportunity to move away from the serial crisis of traditional subscription pricing. We hope that the science funding bodies will recognise the opportunities that learned societies like the IAVS and medium-sized publishers such as Pensoft offer and consider implementing similar deals to the ones they have struck with some mega-publishers.

\section{Open data}

As important as open access to scientific articles is the access to the underlying data. In the last decade, we have seen how the availability of vegetation-plot data at the national (see Dengler et al. 2011) and international level (Chytrý et al. 2016; Dengler et al. 2018; Bruelheide et al. 2019) has fostered cooperation and enabled completely new avenues of research (Bruelheide et al. 2018; Dengler et al. 2020). Hoewever, for vegetation classification there is still much progress to be made. Many of the analytical methods utilised in the production of classifications can generate unstable results, as they are highly dependent on small parts of the input data. The availability of primary data is an indispensable requirement for the reproducibility of ecological research (Reichman et al. 2011).

VCS expects that data will be archived, if possible, in an appropriate public repository or in electronic Supplementary Information connected to the paper. The authors should make a statement of where the primary data are stored. If they are archived in a public repository, a reference to a DOI (digital object identifier) or permanent URL (uniform resource locator) should be provided. If the paper uses data from large multi-contributor databases such as sPlot, EVA (European Vegetation Archive) or TRY, which cannot be made publicly available because of the third-party ownership issues, the data selection released for the study should be stored in a permanent repository and made available for re-analyses upon request. As Chief Editors of VCS we are interested in making all underlying data permanently available to the scientific public on platforms where the data are easily located and in formats that preserve the rich and complex information that is contained within vegetation data. You can expect us, together with related journals, to spearhead the development of new approaches that will improve on the current scattered and inconsistent solutions.

\section{Double-blind}

The second significant change the editorial team have implemented, compared to our predecessor journal, regards the peer review system. Following other journals like Global Ecology and Biogeography, we now have a double-blind review system where not only the reviewers are unknown to the authors but also the other way round (i.e., the authors are unknown to the reviewers).

The discussion whether single-blind reviews discriminate specific authors based on their affiliation, gender and seniority is controversial and the findings context-dependent (Snodgrass 2006; Budden et al. 2008; Webb et al. 2008). However, whether a paper is accepted for publica- 
tion should be made on the basis of the manuscript alone: Are the methods correct, the conclusions substantiated by the results and overall does the contribution advance science? It should not be dependent on circumstances such as who wrote the paper or the professional affiliations of the authors. We have experienced that biases in both directions can occur, whether manuscripts from young, female authors from developing countries are assessed over-critically compared to those from senior, well-known male authors, or the other way around are just waved through despite obvious weaknesses. By introducing double-blind peer review, we want to contribute our part to reducing such biases where they might exist. We are well aware that sometimes authors can be guessed from the manuscript content, but this does not make the approach invalid. Beyond double-blind reviews we will always try to do our best to be fair to all authors, fairness to unknown authors or institutions, fairness to prolific or to less-published authors, as well as gender equity.

\section{The first papers of VCS}

This Editorial goes online together with a group of papers, covering five continents and much of the journal's research spectrum. A study from China examines Pinus yunnanensis forests, a commercially, culturally and economically important tree of south-western China (Tang et al. 2020). We would like to see more vegetation studies from this species-rich region, from both natural and anthropogenically influenced vegetation types. Hunter and Hunter (2020) report on montane mire vegetation

\section{References}

Abutaha M, Elkhouly A, Jürgens N, Oldeland J (2020) Plant communities and their environmental drivers on an arid mountain, Gebel Elba, Egypt. Vegetation Classification and Survey 1: 21-36. https:// doi.org/10.3897/VCS/2020/38644

Antelman K (2004) Do open-access articles have a greater research impact? College \& Research Libraries 65: 372-382. https://doi. org/10.5860/crl.65.5.372

Attorre F, Cambria VE, Agrillo E, Alessi N, Alfò M, De Sanctis M, Malatesta L, Sitzia T, Guarino R, ... Fanelli G (2020) Finite Mixture Model based classification of a complex vegetation system using a large dataset. Vegetation Classification and Survey 1: 77-86. https://doi. org/10.3897/VCS/2020/48518

Biurrun I, Bergmeier E, Dengler J, Jansen F, Willner W (2019) Vegetation classification and its application are relevant globally. Phytocoenologia 49: 1-6. https://doi.org/10.1127/phyto/2019/0323

Bruelheide H, Dengler J, Purschke O, Lenoir J, Jiménez-Alfaro B, Hennekens SM, Botta-Dukát Z, Chytrý M, Field R, ... Jandt U (2018) Global trait-environment relationships of plant communities. Nature Ecology \& Evolution 2: 1906-1917. https://doi.org/10.1038/s41559-018-0699-8 Bruelheide H, Dengler J, Jiménez-Alfaro B, Purschke O, Hennekens SM, Chytrý M, Pillar VD, Jansen F, Kattge J, ... Zverev A (2019) sPlot - a new tool for global vegetation analyses. Journal of Vegetation Science 30: 161-186. https://doi.org/10.1111/jvs.12710 from the New England Tablelands Bioregion in Australia and how it fits into previous classifications. Zeballos et al. (2020) classify dry subtropical forests in the Espinal province, Argentina, using vegetation plots, and call for their urgent conservation. Abutaha et al. (2020) describe the plant communities and their environmental drivers on Gebel Elba, Egypt. Finally, Zervas et al. (2020) present a phytosociological survey of aquatic vegetation in the main freshwater lakes of Greece.

Classification methods in VCS are not limited to any specific approach. This is exemplified by the selection of papers published together with the Editorial. They range from phytosociology (Guarino et al. 2018) to the EcoVeg approach (Faber-Langendoen et al. 2014) and we hope to see many more approaches together with papers that try to unify different approaches. As explained in our scope (see Introduction), we also appreciate methodological papers, such as the one from Attorre et al. (2020), who compare finite mixture models to a more traditional classification method. Such comparisons are fundamental to advance our toolbox for vegetation classification and survey.

\section{Author contributions}

F.J. planned and drafted this editorial while all other authors made significant contributions.

\section{Acknowledgements}

We thank James Martin for linguistic editing.

Budden A, Tregenza T, Aarssen L, Koricheva J, Leimu R, Lortie C (2008) Double-blind review favours increased representation of female authors. Trends in Ecology \& Evolution 23: 4-6. https://doi. org/10.1016/j.tree.2007.07.008

Cheung M (2015) The costs of double dipping. Research Libraries, UK. https:// www.rluk.ac.uk/the-costs-of-double-dipping [accessed 25 Mar 2020]

Chytrý M, Hennekens SM, Jiménez-Alfaro B, Knollová I, Dengler J, Jansen F, Landucci F, Schaminée JHJ, Aćić S, ... Yamalov S (2016) European Vegetation Archive (EVA): an integrated database of European vegetation plots. Applied Vegetation Science 19: 173-180. https://doi. org/10.1111/avsc.12191

Dengler J, Jansen F, Glöckler F, Peet RK, De Cáceres M, Chytrý M, Ewald J, Oldeland J, Lopez-Gonzalez G, ... Spencer N (2011) The Global Index of Vegetation-Plot Databases (GIVD): A new resource for vegetation science. Journal of Vegetation Science 22: 582-597. https:// doi.org/10.1111/j.1654-1103.2011.01265.x

Dengler J, Wagner V, Dembicz I, García-Mijangos I, Naqinezhad A, Boch S, Chiarucci A, Conradi T, Filibeck G, ... Biurrun I (2018) GrassPlot - a database of multi-scale plant diversity in Palaearctic grasslands. Phytocoenologia 48: 331-347. https://doi.org/10.1127/ phyto/2018/0267

Dengler J, Matthews TJ, Steinbauer MJ, Wolfrum S, Boch S, Chiarucci A, Conradi T, Dembicz I, Marcenò C, ... Biurrun I (2020) Spe- 
cies-area relationships in continuous vegetation: Evidence from $\mathrm{Pa}$ laearctic grasslands. Journal of Biogeography 60: 72-86. https://doi. org/10.1111/jbi.13697

Evans JA, Reimer J (2009) Open access and global participation in science. Science 323: 1025-1025. https://doi.org/10.1126/science. 1154562

Eysenbach G (2006) Citation advantage of open access articles. PLoS Biology 4: e157. https://doi.org/10.1371/journal.pbio.0040157

Faber-Langendoen D, Keeler-Wolf T, Meidinger D, Tart D, Hoagland B, Josse C, Navarro G, Ponomarenko S, Saucier JP, ... Comer P (2014) EcoVeg: a new approach to vegetation description and classification. Ecological Monographs 84: 533-561. https://doi.org/10.1890/13-2334.1

Geschuhn K (2015) Disrupting the subscription journals' business model for the necessary large-scale transformation to open access: A Max Planck Digital Library Open Access Policy White Paper. ScienceOpen Research. [accessed 25 Mar 2020] https:/doi.org/10.14293/ S2199-1006.1.SOR-EDU.AJRG23.v1

Guarino R, Willner W, Pignatti S, Attorre F, Loidi J (2018) Spatio-temporal variations in the application of the Braun-Blanquet approach in Europe. Phytocoenologia 48: 239-250. https://doi.org/10.1127/ phyto/2017/0181

Hunter JT, Hunter VH (2020) Montane mire vegetation of the New England Tablelands Bioregion of Eastern Australia. Vegetation Classification and Survey 1:37-51. https://doi.org/10.3897/VCS/2020/48765

Jansen F, Bergmeier E, Dengler J, Janišová M, Krestov P, Willner W (2016) Vegetation classification: A task of our time. Phytocoenologia 46: 1-4. https://doi.org/10.1127/phyto/2016/0134

Laakso M, Welling P, Bukvova H, Nyman L, Björk BC, Hedlund T (2011) The development of open access journal publishing from 1993 to 2009. PLoS ONE 6: e20961. https://doi.org/10.1371/journal. pone.0020961

McGuigan GS, Russell RD (2008) The business of academic publishing: a strategic analysis of the academic journal publishing industry and its impact on the future of scholarly publishing. Electronic Journal of Academic and Special Librarianship. http://southernlibrarianship.icaap. org/content/v09n03/mcguigan_g01.html [accessed 25 March 2020]
Reichman OJ, Jones MB, Schildhauer MP (2011) Challenges and opportunities of open data in ecology. Science 331: 703-705. https://doi. org/10.1126/science.1197962

Snodgrass R (2006) Single- versus double-blind reviewing: An analysis of the literature. ACM SIGMOD Record 35: 8-21. https://doi. org/10.1145/1168092.1168094

Springer Nature, MPDL Services (2020) Publish and Read Agreement Projekt DEAL and Springer Nature. https://doi. org/10.17617/2.3174351

Tang CQ, Shen LQ, Han PB, Huang DS, Li S, Li YF, Song K, Zhang ZY, Yin LY, ... Xu HM (2020) Forest characteristics, population structure and growth trends of Pinus yunnanensis in Tianchi National Nature Reserve of Yunnan, southwestern China. Vegetation Classification and Survey 1: 7-20. https://doi.org/10.3897/VCS/2020/37980

Tennant JP, Waldner F, Jacques DC, Masuzzo P, Collister LB, Hartgerink, CHJ (2016) The academic, economic and societal impacts of Open Access: An evidence-based review. F1000Research 5: 1-54. https:// doi.org/10.12688/f1000research.8460.3

van der Maarel E (1990) The Journal of Vegetation Science - a journal for all vegetation scientists. Journal of Vegetation Science 1: 1-4. https:// doi.org/10.1111/j.1654-1103.1999.tb00576.x

Webb TJ, O'Hara B, Freckleton RP (2008) Does double-blind review benefit female authors? Trends in Ecology \& Evolution 23: 351-353. https://doi.org/10.1016/j.tree.2008.03.003

Wiley, MPDL Services (2019) Publish and Access Agreement Projekt DEAL and Wiley. https://www.projekt-deal.de/about-deal [accessed 25 March 2020]

Zeballos S, Giorgis M, Cabido M, Acosta A, Iglesias MR, Cantero J (2020) The southern extreme of seasonally dry subtropical forests in South America: Vegetation types and a call for conservation. Vegetation Classification and Survey 1: 87-102. https://doi.org/10.3897/ VCS/2020/38013

Zervas D, Tsiripidis I, Bergmeier E, Tsiaoussi V (2020) A phytosociological survey of aquatic vegetation in the main freshwater lakes of Greece. Vegetation Classification and Survey 1: 53-75. https://doi. org/10.3897/VCS/2020/48377

\section{E-mail and ORCID}

Florian Jansen (Corresponding author, florian.jansen@uni-rostock.de), ORCID: https://orcid.org/0000-0002-0331-5185

Idoia Biurrun (idoia.biurrun@ehu.eus), ORCID: https://orcid.org/0000-0002-1454-0433

Jürgen Dengler (juergen.dengler@uni-bayreuth.de), ORCID: https://orcid.org/0000-0003-3221-660X

Wolfgang Willner (wolfgang.willner@univie.ac.at), ORCID: https://orcid.org/0000-0003-1591-8386 